\title{
Applying Uncertain Science to Nature-Based Coastal Protection: Lessons From Shallow Wetland-Dominated Shores
}

\author{
Iris Möller* \\ Cambridge Coastal Research Unit, Department of Geography, University of Cambridge, Cambridge, United Kingdom
}

Climate change and associated sea-level rise alongside the potential for alterations in the magnitude and frequency of extreme storm events, rapidly rising coastal populations, and a legacy of coastal land reclamation are forcing the need for sustainable coastal protection on shallow, wetland-dominated coasts. In this context, practitioners, and academics in the field of coastal flood and erosion risk reduction have been highlighting

OPEN ACCESS

Edited by:

Rene Friedland,

Joint Research Centre, Italy

Reviewed by:

Kerrylee Rogers,

University of Wollongong, Australia

Giulio Mariotti,

Louisiana State University,

United States

Neil Ganju,

Woods Hole Coastal and Marine

Science Center, United States Geological Survey, United States

Dorte Krause-Jensen,

Aarhus University, Denmark

*Correspondence:

Iris Möller

imcoasts@gmail.com

Specialty section:

This article was submitted to Marine Pollution,

a section of the journal

Frontiers in Environmental Science

Received: 14 December 2018 Accepted: 28 March 2019

Published: 24 April 2019

Citation:

Möller I (2019) Applying Uncertain Science to Nature-Based Coastal Protection: Lessons From Shallow

Wetland-Dominated Shores.

Front. Environ. Sci. 7:49.

doi: 10.3389/fenvs.2019.00049 the flood protection value of natural coastal features for some time. Examples of the implementation of nature-based coastal flood and erosion risk reduction schemes, however, are few and far between and can certainly not (yet) be considered mainstream. One key problem around the implementation of these types of approaches has arguably been the relative lack of perceived scientific certainty around the efficiency with which natural landforms, such as coastal wetlands, reduce wave action on landward lying structures and the persistence of such landforms in an uncertain future. This makes nature-inclusive approaches less attractive to more traditional engineering-only approaches that rely solely on one "hard" structure with a well-defined impact on waves and a specified design life. Using the example of wave dissipation over coastal wetland surfaces, this paper provides a way forward for an easily applicable scientifically informed assessment of the minimum difference any given wetland makes to wave heights at landward locations. Such a "minimum function" approach could be rolled out to other ecosystem services provided by natural features and thus allow decision makers and coastal planners to consider nature-inclusive approaches to coastal management with greater confidence.

Keywords: nature-based adaptation, coastal protection and management, coastal wetlands, science-policy advice, flood and erosion risk

\section{THE NEED FOR LONG-TERM COASTAL PROTECTION SOLUTIONS}

"Coastal protection" (CP) generally refers to the protection of people, infrastructure, and other assets from the negative consequences resulting from flooding (high water levels and/or wave overtopping) and erosion. The need for human intervention for the purpose of CP arises where either (i) the occurrence of flooding and erosion has thus far neither been continuous nor frequent (and thus not threatening) enough to prevent the presence of people and assets at the coast or (ii) existing CP solutions have become obsolete or not fit for purpose. The latter may be the results of 
changing external conditions (e.g., climate change induced rise in sea level or storm intensity), or reduced functionality of the CP features present (e.g., engineered sea defenses approaching the end of their design life).

The most recent Intergovernmental Panel on Climate Change Fifth Assessment Report (IPCC AR5) and the follow up report on the implications of a global rise in temperatures of $1.5^{\circ} \mathrm{C}$ released in October 2018 (IPCC, 2018) have highlighted the urgent need to mitigate against future coastal flood and erosion risk due to predicted changes in external conditions. National assessments, such as the UK Met Office's Climate Projections (Fung et al., 2018) have been quick to follow and to translate global and regional projections to specific coastal contexts for this purpose.

The realization that engineered defences may not be the most sustainable CP solution has accompanied this recognition of enhanced flood and erosion risk under changing external conditions. Many now call for "nature-based-solutions" (variously also referred to as "living shorelines," "soft infrastructure," or other) to achieving CP. Such approaches often involve the preservation and/or restoration of "soft" coastal landforms such as dunes and coastal wetlands that act as natural wave and tidal flow dissipaters (Kabat et al., 2009; Narayan et al., 2017). Unlike engineered hard structures, however, natural landforms dynamically adjust to external drivers (e.g., wave and/or tidal energy). This adjustment means that natural landforms can potentially persist where engineered structures cannot. It also means that natural coastal protection requires more space than engineered defenses. Coastal populations are often reliant on fixed infrastructure (roads, houses, industries) with a smaller "footprint" and this leads to conflicts with the space required for morphodynamic landform adjustments to higher sea levels and altered wave climates.

This problem of high human development pressures alongside the requirement for space to allow natural $\mathrm{CP}$ features to adjust (often through landward migration) is amplified on low-lying bordering coasts, many of which, such as the Wadden Sea and The Wash the North Sea and the Mississippi delta coast on the Gulf of Mexico are fringed by wetlands. One key compounding factor is that it is precisely those coasts (low-lying areas with fertile, cohesive sediments) that have lent themselves to land reclamation. The construction of artificial dikes, seawalls, or embankments, has arguably exacerbated the situation in that it has led to the creation of a false sense of security and an associated rise in populations in flood prone areas (Rumson et al., 2017). Solutions that incorporate the buffering function of coastal wetlands and reduce the exposure of coastal populations, industry, and infrastructure, to flood and erosion risk on such low-lying shores, are thus particularly urgently needed.

\section{NATURAL PROTECTION PROVIDED BY COASTAL WETLANDS: SCIENTIFIC CONSIDERATIONS}

Scientific evidence for the protection provided by coastal wetlands has been mounting over the past two decades and there is now no doubt about the mechanisms at play that result in such protection. The buffering function of wetlands is a result of both, (a) the wetland's cohesive materials which produce landforms high in the intertidal zone (see e.g., Allen, 2000) that are relatively less dynamic (on daily wave/tide time scales) than non-cohesive sandy equivalents (e.g., beaches) and (b) the wetland's surface characteristics (dense vegetation canopies) which, when inundated retard waves and the mass flux of water (Anderson and Smith, 2014; Möller and Christie, 2018). These two processes are clearly closely connected as the latter has also been shown to affect the former (sediment deposition and thus landform evolution itself) (Hendriks et al., 2008; Duarte et al., 2013; Gattuso et al., 2018).

As regards (a), surface elevation exerts a key control on the perennial vegetation cover, i.e., such vegetation only establishes at elevations at which the salt-tolerant, but terrestrial, plant species can withstand periodic inundation of limited frequency and duration. Thus, wetlands in NW Europe, for example, typically result in vegetated surfaces at or above mean high water neap tide level (Suchrow and Jensen, 2010) and even on mega-tidal coasts, such as those of the Bay of Fundy in Canada, water depths above the vegetated wetland surface rarely exceed $2 \mathrm{~m}$ (DavidsonArnott et al., 2002). The process of continued vegetation growth, sediment accumulation and soil formation thus creates relatively stable near-horizontal surfaces and much shallower extreme water depths close to the shoreline than would otherwise be the case.

As regards (b), proof now exists that, even under extreme storm surge conditions (such as those experienced in the North Sea in 1953 and 2013) with above-marsh water depths of around $2 \mathrm{~m}$, a NW European salt marsh of a width of only $40 \mathrm{~m}$ reduces non-breaking waves by $14-15 \%$ in height (Möller et al., 2014). River flooding may add significantly to flood water volumes such that water depths above the wetland surface may exceed $2 \mathrm{~m}$. In such fetch-limited estuarine settings, however, wave heights are less likely to be of concern. This also applies to mangrove-fringed coasts, where the vegetation canopy remains emergent during extreme wind-generated wave conditions and wave energy is even more efficiently dissipated (McIvor et al., 2015). On more exposed shores, the overtopping risk of landward sea defenses, whether natural (e.g., dunes) or constructed by humans (e.g., sea wall) is thus markedly reduced in the presence of wetlands and societies on wetland coasts have benefitted from this particular ecosystem service for many centuries.

The transfer of this knowledge into practical solutions that acknowledge this flood and erosion risk reduction through wetlands, however, has proven to be a greater challenge than might be expected. The reasons for this are manifold but are partly to be found in the nature of the problem itself: the inherent variability, uncertainty, context-dependency, and nonlinear evolution of landform behavior and morphodynamic feedback is something geomorphologists are only too familiar with [see, for example Cowell and Thom (1994)], but that does not lend itself to engineering approaches with expectations of defined outcomes and a specified design life.

Without expected defined outcomes and design life estimates available for nature-inclusive $\mathrm{CP}$ options, it is difficult to sustain an argument for such options, particularly where a case has to 
be made for a reduced cost (resulting from a reduced design specification of the engineering component) of a nature-inclusive approach. As a result, the existing implementation of "managed realignment" as a "nature-based coastal protection" solution, for example, has so far been more often than not driven by nature conservation, rather than $\mathrm{CP}$ (or at least wave dissipation), objectives (Esteves, 2014; Esteves and Williams, 2017).

\section{TOWARD A SIMPLE SCIENTIFICALLY-INFORMED LOCATION-SPECIFIC ASSESSMENT OF NATURAL COASTAL PROTECTION PROVIDED BY WETLANDS}

Given the wide range of projections of climate-change induced alterations in coastal hydrodynamics on any given coast, most notably the frequency distribution of water levels and wave conditions of particular magnitude, we need to get better at making decisions in the face of uncertainty. The suggestion here is that we need to re-think how we deal with uncertain future behavior of coastal landforms and thus their natural CP function. The question we might thus ask is: "what is certain within the uncertain?" and then "what are the implications of what is certain for our decision-making?"

By way of an illustration of an approach that may more easily guide decision-making, it is helpful to consider the wave dissipation function of coastal wetland vegetation. We can thus apply the above questions to existing knowledge on the wave dissipation provided by natural coastal wetland landforms/ecosystems to (i) translate what we know with scientific certainty into "necessary" conditions that have to be met for wave dissipation to take place and (ii) look for conditions that determine the relative degree of dissipation. Thus, the most basic necessary condition for wetlands to contribute to wave dissipation is the occurrence of onshore directed waves (see Figure 1A). This may seem obvious, but is, in the author's experience, surprisingly often ignored or not explicitly mentioned in communications between scientists and lay audiences, policy-makers, and stakeholders who are unfamiliar with coastal processes. Wetlands only fulfill their wave dissipation function when waves travel toward the shore. Thus the frequency with which waves can be expected to do so is critical in justifying the inclusion of coastal wetlands within CP planning. Where off-shore winds prevail and onshore winds occur only infrequently, with low wind speeds and/or short duration, the natural wave dissipation function is thus by definition negligible [in the case of the wind conditions shown in Figure 1A, this would be the case on any NE exposed shores of this fictional arrangement of coastal settings (Figure 1B)]. Most importantly for the discussion here, perhaps, this assessment can be made without the need for complex numerical modeling and through a relatively simple analysis of past (or likely future) meteorological conditions at the site of interest.

Once established that onshore winds/waves are likely enough (given the user/stakeholder's concerns), the importance of an individual wetland's contribution to wave dissipation in that context can be considered. For this, it is important to recognize that shallow water wave heights will never exceed their theoretical maximum for a given water depth. Notwithstanding nonlinear shallow-water effects, we know that wave breaking occurs approximately as $\mathrm{H} / \mathrm{h}(\mathrm{H}=$ wave height and $\mathrm{h}=$ water depth) approaches a value of 0.78 (Komar, 1998). This alone gives (a) certainty that the relatively lower water depths present over the wetland surfaces result in lower maximum wave heights $(\mathrm{H})$ than on adjacent surfaces at lower elevations / in deeper water and, (b) generally limits any waves that are present to locally generated waves (as swell waves shoal and break well before they reach the wetland margin). Knowledge of the maximum water depth above the wetland surface is the key parameter in this context (Figure 1C). Local knowledge may offer a way forward for estimating worst-case-scenario water levels in situations where direct hydrological and/or meteorological data is not available.

Whether or not wave heights reach their theoretical maximum close to their breaking limit before they reach the wetland landform, fundamentally depends on the fetch distance, wind direction and wind duration (Komar, 1998), which in turn depends on the wetland setting or geographical context (see Figure 1). Thus, wave dissipation over wetlands on exposed coasts (potential large fetch and/or high wind speeds and/or slow moving storms) will likely be of greater significance from a CP perspective than that of wetlands on more sheltered shores (see also Figure $\mathbf{1 B}$ for an indication of different wetland settings). As the intention here is to guide the practitioner toward a confident end statement, however, this consideration is best made only after ensuring that the width of the wetland surface matches or exceeds that for which scientific evidence exists (Figure 1D).

Finally, all other considerations being equal (magnitude and frequency of winds generating waves in an onshore direction), we know that the dissipation of waves depends on three further generic factors: (i) topographic and (ii) vegetation induced bed roughness of the wetland surface and (iii) the relative wave height (or wave height to water depth ratio) during any given inundation event (Moeller et al., 1996; Möller et al., 1999).

At this point it is important to consider the interests of potential stakeholders in this problem. Where their concern is primarily around flood risk, any scientific advice providing guidance on the minimum protection offered, with relative certainty, is useful. Further, such advice is arguably more useful than providing advice on average protection offered but with less certainty. Thus, as we now know that a lower water level, an increase in topographic roughness and an increase in the height, density, and rigidity of the vegetation will lead to an increase in wave dissipation (Möller, 2006; Anderson et al., 2013; Anderson and Smith, 2014; Paul et al., 2016), we can be certain that the expected wave dissipation will always be equal to, or greater than, that which occurs over a horizontal, topographically smooth, platform covered in short, flexible vegetation and inundated to maximum water depth. In the example shown in Figure 1D, the case is made for dense north-west European salt marsh [Figure 1D (7)].

The argument here is that the above method would allow a relative assessment of the expected minimum wave dissipation provided by existing wetland surfaces, even in a situation in which only basic site information is available. Furthermore, the method allows stakeholders to "model" scenarios of wind 

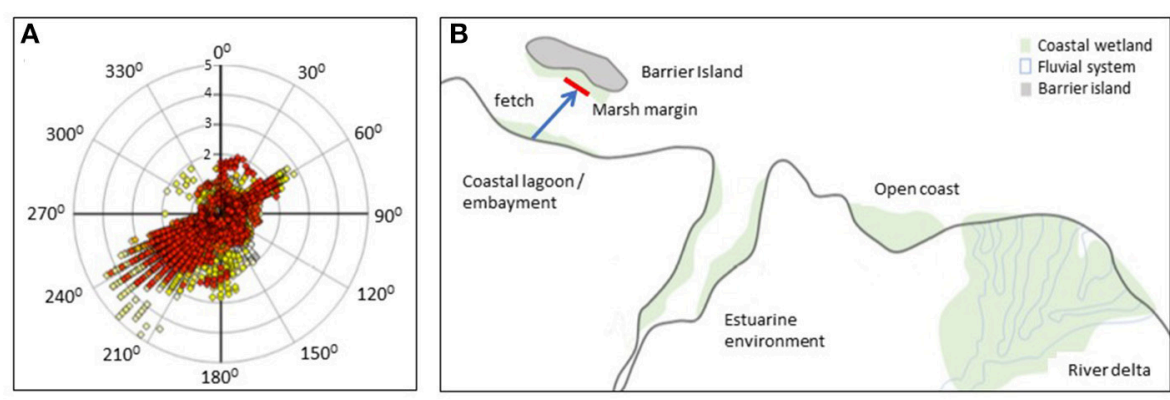

\section{C \\ (1)}

Wind speed/frequency/direction from
regional/local station
(use of existing met. Data-see A)
$\begin{aligned} & \text { Frequency/magnitude of wetland } \\ & \text { fronting water depths, including } \\ & \text { extreme tide/surge conditions }\end{aligned}$
(taking account of wave breaking criterion)

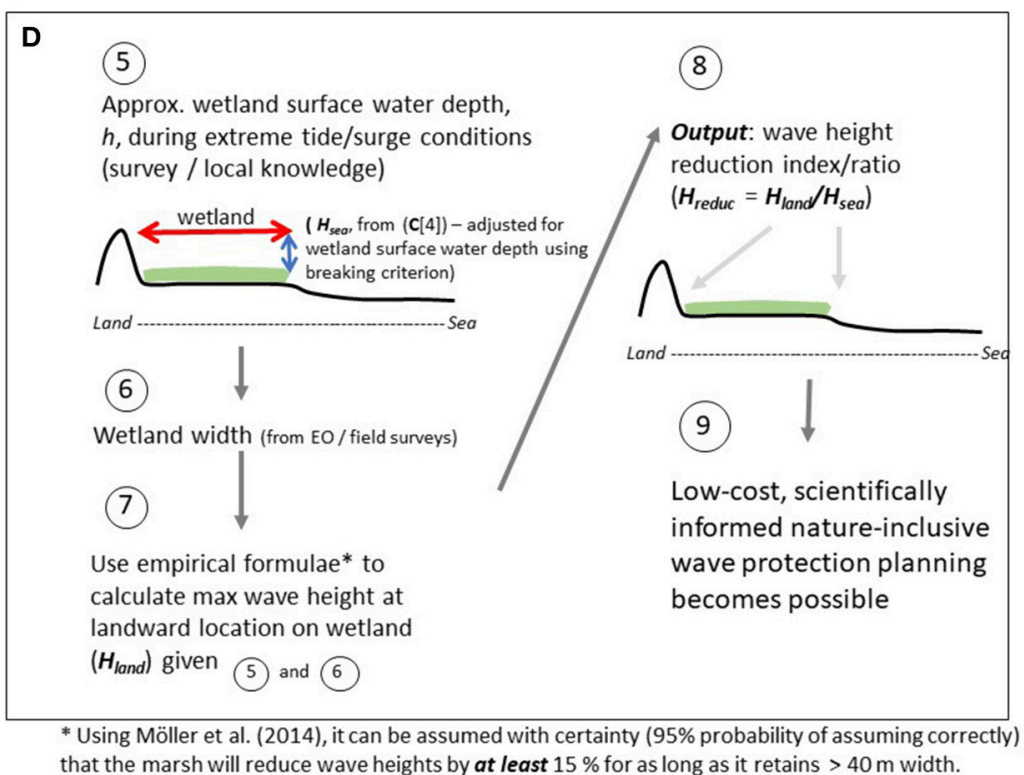

FIGURE 1 | Steps by which wave height at the seaward and landward limit of the wetland can be compared. Wind speed and direction [A,C(1)] in any particular coastal setting (B) combine with water depth at the front of the wetland $[\mathbf{C}(2)]$ and the fetch distance over which the wind blows [C(3)] to generate maximum wave heights achievable at the wetland front [C(4)]. In (D) wetland surface elevation and wave breaking limit maximum water depths and wave heights, respectively, at the seaward wetland margin (5); wetland width (6) and empirical formulae (7) allow an estimate of maximum wave heights at a distance $>40 \mathrm{~m}$ inland of the wetland margin (8). Red line and blue arrow in (B) illustrate location of wetland margin and fetch distance for a specific fetch-limited marsh setting; in other settings, waves may be depth- rather than fetch-limited (open coast) or onshore winds may be rare/weak (any north-west exposed shore in the given example).

directions and speeds that have thus far not occurred but may occur in the future. It also provides confidence that the actual wave dissipation provided by the landform will in all likelihood be more than the expected minimum calculated. This means that the case for action on behalf of those deciding to invest in the maintenance or restoration of the natural feature (in this case a coastal wetland) can be more meaningfully made. Equally importantly, the information that allows such an assessment to be made is becoming increasingly and more readily available as airborne and satellite remote sensing techniques are being developed.

The above methodology delivers qualitative comparisons between the wave protection provided by wetlands in different settings/locations and allows for the powerful option to compare 
"alternative states" of a particular shore, e.g., the presence or absence of a particular wetland, for the purpose of assessing the contribution of coastal wetlands to flood and erosion risk, without the need for complex numerical models. In terms of considerations of new wetland design and construction for the purpose of wave energy dissipation, such interventions would clearly also require a broader consideration of impacts on local/regional hydrodynamics, ecology, and geomorphology. Where rapid assessments of flood and erosion risk mitigation options are required and/or resources are sparse, however, the use of readily available data for an assessment of "either/or" type decisions and to explore the existing role of wetlands as natural $\mathrm{CP}$ features is an attractive option. The example used here (Figure 1D) is specifically built around the outputs of one specific scientific study (Möller et al., 2014) but the approach it illustrates is more widely applicable.

\section{OUTLOOK}

The above approach represents one way forward toward the wider incorporation of current, inherently uncertain, scientific knowledge into coastal management decision making. It has already been incorporated into the "Toolkit for Ecosystem Services Site-based Assessment (TESSA)" (Peh et al., 2017) methodology for the assessment of a range of ecosystem services provided by specific sites, including wave dissipation provided by coastal wetlands. Three key contextual issues affecting the application of these types of approaches are worth highlighting here:

First, it is important to take a holistic view of the many cobenefits arising from coastal ecosystems more widely, notably carbon storage and sequestration (Duarte et al., 2013; Gattuso et al., 2018; Rogers et al., 2019), denitrification (Sousa et al., 2011), biodiversity conservation, recreation, and the provision of agricultural goods and services (e.g., fish habitat) (Costanza et al., 1997), all of which are delivered alongside the CP function.

Second, the interconnected nature of co-existing coastal wetland ecosystems must be considered in light of the above. Thus, Valiela and Cole (2002) for example provide evidence for the interconnectedness of mangroves, salt marshes and sea grasses, all of which deliver a range of ecosystem services.

Third, and clearly connected to this issue of interdependency of ecosystems, is the consideration of an individual wetland's resilience in the face of changing environmental conditions over time. Coastal landforms, unlike engineered defenses, are able to evolve and respond to hydrodynamic and ecological forcing conditions. This means that their future cannot easily be predicted with any degree of accuracy but also means that, given adequate space to evolve and given their resilience in terms of vertical stability (Spencer et al., 2016a), coastal wetlands such as salt marshes can continue to provide $\mathrm{CP}$ at times of environmental change. The answer to the question "what can we be certain about with respect to the reduction of waves over this wetland in the future?" could simply be that this depends on the likelihood of the marsh exceeding a width of $40 \mathrm{~m}$ at that point in time (see example in Figure 1D). As there is concrete scientific evidence for the reduction of waves over a $40 \mathrm{~m}$ wide saltmarsh and marsh surfaces are unlikely to erode vertically (Spencer et al., 2016a), the above methods are applicable as long as there is sufficient evidence that marsh width will remain at $40 \mathrm{~m}$ or greater over the desired management time-scale. The uncertainty around potential marsh erosion thus really only hampers decision making where it encompasses the possibility of marsh widths reducing to below $40 \mathrm{~m}$. This greatly enhances the number of scenarios/locations where the incorporation of existing marshes into $\mathrm{CP}$ schemes becomes possible. In time, the application of a growing body of evidence on the likely future evolution of coastal wetlands in any one location under a range of external conditions [e.g., climate change and associated impacts such as sea level rise, eutrophication (Duarte and KrauseJensen, 2018), and altered sediment supply (Spencer et al., 2016b)] will allow similar approaches to that outlined above for wave dissipation.

\section{CONCLUSION}

Scientific uncertainty around the variability of wave dissipation over coastal wetland surfaces on the one hand and lack of certainty around the future existence of coastal wetlands on the other may frequently be cited as reasons for the lack of consideration of these features in the design and planning of CP schemes. The above considerations, based on wellestablished scientific developments over the past decade or two, however, show that one way forward may be to apply a logical approach in which existing science is used to estimate the "minimum functionality" of a coastal landform (in this case coastal wetlands) with respect to a particular desired effect (in this case wave dissipation). To maximize the policy-use of existing science, such approaches should be more widely advocated amongst the coastal management and coastal flood and erosion protection community.

\section{AUTHOR CONTRIBUTIONS}

The entire article was written by IM, reference to existing work published elsewhere has been made wherever appropriate.

\section{ACKNOWLEDGMENTS}

The data and insights reported in this paper are the result of the author's research as part of a series of research projects funded by the UK Natural Environment Research Council (projects CBESS NERC NE/J015350/1, BLUEcoast NE/N015878/1, CoastWEB NE/N013573/1 and RESIST NE/R01082X/1), the European Union FP7-SPACE FAST and the European Community's Horizon 2020 Research and Innovation Programme through the grant to HYDRALA-PLUS, Contract no. 654110, and the Newton Trust, Cambridge, all of whom are acknowledged for their support. The discussions with colleagues on those projects have shaped and guided the reasoning expressed and the author thanks all concerned for these many opportunities. 


\section{REFERENCES}

Allen, J. R. L. (2000). Morphodynamics of holocene salt marshes: a review sketch from the atlantic and Southern North Sea coasts of Europe. Quat. Sci. Rev. 19, 1155-1231. doi: 10.1016/S0277-3791(99)00034-7

Anderson, K., Rossini, M., Pacheco-Labrador, J., Balzarolo, M., Mac Arthur, A., Fava, F., et al. (2013). Inter-comparison of hemispherical conical reflectance factors (HCRF) measured with four fibre-based spectrometers. Opt. Expr. 21, 605-617. doi: 10.1364/OE.21.000605

Anderson, M. E., and Smith, J. M. (2014). Wave attenuation by flexible, idealized salt marsh vegetation. Coast. Eng. 83, 82-92. doi: 10.1016/j.coastaleng.2013.10.004

Costanza, R., D’Arge, R., de Groot, R., Farber, S., Grasso, M., Hannon, B., et al. (1997). The value of the world's ecosystem services and natural capital. Nature $387,253-259$.

Cowell, P., and Thom, B. (1994). "Morphodynamics of coastal evolution," in Coastal evolution: Late Quaternary Shoreline Morphodynamics, eds R. Carter and C. Woodroffe (Cambridge: Cambridge University Press), 33-86.

Davidson-Arnott, R. G. D., van Proosdij, D., Ollerhead, J., and Schostak, L. (2002). Hydrodynamics and sedimentation in salt marshes: examples from a macrotidal marsh, Bay of Fundy. Geomorphology 48, 209-231. doi: 10.1016/S0169-555X(02)00182-4

Duarte, C. M., and Krause-Jensen, D. (2018). Intervention options to accelerate ecosystem recovery from coastal eutrophication. Front. Mar. Sci. 5, 1-8. doi: 10.3389/fmars.2018.00470

Duarte, C. M., Losada, I. J., Hendriks, I. E., Mazarrasa, I., and Marbà, N. (2013). The role of coastal plant communities for climate change mitigation and adaptation. Nat. Clim. Chang. 3, 961-968. doi: 10.1038/nclimate1970

Esteves, L. S. (2014). Managed Realignment: A Viable Long-Term Coastal Management Strategy? SpringerBriefs in Environmental Science. New York, NY: Springer.

Esteves, L. S., and Williams, J. J. (2017). "Managed realignment in Europe: a synthesis of methods, achievements and challenges," in Living Shorelines: The Science and Management of Nature-based Coastal Protection, eds D. M. Bilkovic, M. M. Mitchell, J. D. Toft, and L. P. K. Megan (Taylor: CRC Press \& Francis Group), 157-180.

Fung, F., Palmer, M., Howard, T., Lowe, J., Maisey, P., and Mitchell, J. F. B. (2018). UKCP18 Factsheet: Sea Level Rise and Storm Surge, Met Office Hadley Centre, Exeter. Available online at: https://www.metoffice.gov.uk/binaries/content/ assets/mohippo/pdf/ukcp18/ukcp18-fact-sheet-sea-level-rise-and-stormsurge.updated-02.19.pdf

Gattuso, J. P., Mcleod, E., Chalastani, V. I., Bopp, L., Billé, R., Middelburg, J. J., et al. (2018). Ocean solutions to address climate change and its effects on marine ecosystems. Front. Mar. Sci. 5:337. doi: 10.3389/fmars.2018.00337

Hendriks, I. E., Sintes, T., Bouma, T. J., and Duarte, C. M. (2008). Experimental assessment and modeling evaluation of the effects of the seagrass Posidonia oceanica on flow and particle trapping. Mar. Ecol. Prog. Ser. 356, 163-173. doi: $10.3354 /$ meps 07316

IPCC (2018). IPCC Special Report on the Impacts of Global Warming of $1.5^{\circ} \mathrm{C}$ Summary for Policy Makers. Available online at: http://www.ipcc.ch/report/ sr15/

Kabat, P., Fresco, L. O., Stive, M. J. F., Veerman, C. P., van Alphen, J. S. L. J., Parmet, B. W. H., et al. (2009). Dutch coasts in transition. Nat. Geosci. 2, 450-452. doi: $10.1038 /$ ngeo572

Komar, P. D. (1998). Beach Processes and Sedimentation. New Jersey, NJ: Prentice Hall.

McIvor, A., Spencer, T., Spalding, M., Lacambra, C., and Möller, I. (2015). "Mangroves, Tropical Cyclones, and Coastal Hazard Risk Reduction," in Coastal and Marine Hazards, Risks, and Disasters, eds J. F. Shroder, J. T. Ellis, and D. J. Sherman (Amsterdam: Elsevier), 403-430.
Moeller, I., Spencer, T., and French, J. R. (1996). Wind wave attenuation over saltmarsh surfaces: preliminary results from Norfolk, England. J. Coast. Res. 12, $1009-1016$

Möller, I. (2006). Quantifying saltmarsh vegetation and its effect on wave height dissipation: results from a UK East coast saltmarsh. Estuar. Coast. Shelf Sci. 69, 337-351. doi: 10.1016/j.ecss.2006.05.003

Möller, I., and Christie, E. (2018). "Water Flow in Coastal Wetlands," in Coastal Wetlands. An Integrated Ecosystem Approach, eds G. M. E. Perillo, E. Wolanski, D. R. Cahoon, and C. S. Hopkinson (Amsterdam: Elsevier), 289-323.

Möller, I., Kudella, M., Rupprecht, F., Spencer, T., Paul, M., van Wesenbeeck, B. K., et al. (2014). Wave attenuation over coastal salt marshes under storm surge conditions. Nat. Geosci. 7, 727-731. doi: 10.1038/ngeo2251

Möller, I., Spencer, T., French, J. R., Leggett, D. J., and Dixon, M. (1999). Wave transformation over salt marshes: a field and numerical modelling study from north Norfolk, England. Estuar. Coast. Shelf Sci. 49, 411-426. doi: 10.1006/ecss. 1999.0509

Narayan, S., Beck, M. W., Wilson, P., Thomas, C. J., Guerrero, A., Shepard, C. C., et al. (2017). The value of coastal wetlands for flood damage reduction in the Northeastern USA. Sci. Rep. 7, 1-12. doi: 10.1038/s41598-017-09269-z

Paul, M., Rupprecht, F., Möller, I., Bouma, T. J., Spencer, T., Kudella, M., et al. (2016). Plant stiffness and biomass as drivers for drag forces under extreme wave loading : a fl ume study on mimics. Coast. Eng. 117, 70-78. doi: 10.1016/j.coastaleng.2016.07.004

Peh, K. S. H., Balmford, A. P., Bradbury, R. B., Brown, C., Butchart, S. H. M., Hughes, F. M. R., et al. (2017). Toolkit for Ecosystem Service Site-based Assessment (TESSA). Available online at: http://tessa.tools/

Rogers, K., Kelleway, J. J., Saintilan, N., Megonigal, P., Adams, J. B., Holmquist, J. R., et al. (2019). Wetland carbon storage controlled by millennial-scale variation in relative sea-level rise. Nature 567, 91-96. doi: 10.1038/s41586-019-0951-7

Rumson, A. G., Hallett, S. H., and Brewer, T. R. (2017). Coastal risk adaptation: the potential role of accessible geospatial Big Data. Mar. Policy 83, 100-110. doi: $10.1016 /$ j.marpol.2017.05.032

Sousa, A., Risgaard-Petersen, N., Lillebø, A., Pardal, M., and Caçador, I. (2011). Denitrification: an ecosystem service provided by salt marshes. Mar. Ecol. Prog. Ser. 448, 79-92. doi: 10.3354/meps09526

Spencer, T., Möller, I., Rupprecht, F., Bouma, T. J., van Wesenbeeck, B. K., Kudella, M., et al. (2016a). Salt marsh surface survives true-to-scale simulated storm surges. Earth Surf. Process. Landforms 41, 543-552. doi: 10.1002/ esp. 3867

Spencer, T., Schuerch, M., Nicholls, R. J., Hinkel, J., Lincke, D., Vafeidis, A. T., et al. (2016b). Global coastal wetland change under sea-level rise and related stresses: The DIVA Wetland Change Model. Glob. Planet. Change 139, 15-30. doi: 10.1016/. .gloplacha.2015.12.018

Suchrow, S., and Jensen, K. (2010). Plant species responses to an elevational gradient in german north sea salt marshes. Wetlands 30, 735-746. doi: 10.1007/s13157-010-0073-3

Valiela, I., and Cole, M. L. (2002). Comparative evidence that salt marshes and mangroves may protect seagrass meadows from land-derived nitrogen loads. Ecosystems 5, 92-102. doi: 10.1007/s10021-001-0058-4

Conflict of Interest Statement: The author declares that the research was conducted in the absence of any commercial or financial relationships that could be construed as a potential conflict of interest.

Copyright (C) 2019 Möller. This is an open-access article distributed under the terms of the Creative Commons Attribution License (CC BY). The use, distribution or reproduction in other forums is permitted, provided the original author $(s)$ and the copyright owner(s) are credited and that the original publication in this journal is cited, in accordance with accepted academic practice. No use, distribution or reproduction is permitted which does not comply with these terms. 